\title{
SISTEMÁTICA DEL GÉNERO ABELIA (CAPRIFOLIACEAE) EN MÉXICO
}

\author{
José Á. Villarreal-Quintanilla ${ }^{1,4}$, José Luis Villaseñor-Ríos ${ }^{2}$ \\ Y EDUARDO ESTRADA-CASTILLÓN ${ }^{3}$
}

\begin{abstract}
${ }^{1}$ Universidad Autónoma Agraria Antonio Narro, Departamento de Botánica, Calzada Antonio Narro 1923, 25315 Buenavista, Saltillo, Coahuila, México.

${ }^{2}$ Universidad Nacional Autónoma de México, Instituto de Biología, Departamento de Botánica, Apdo. postal 70-233, Ciudad Universitaria, 04510 México, D.F., México.

${ }^{3}$ Universidad Autónoma de Nuevo León, Facultad de Ciencias Forestales, Apdo. postal 41. 67700 Linares, Nuevo León, México.

${ }^{4}$ Autor para la correspondencia: javillarrea100@hotmail.com
\end{abstract}

\section{RESUMEN}

El género Abelia (Caprifoliaceae) comprende un grupo de plantas arbustivas distribuidas en las regiones templadas y montañosas del este de Asia y América. Se caracteriza por tener sépalos persistentes, corola infundibuliforme o tubular y fruto capsular trilocular indehiscente. En América sólo se conoce de nuestro país y todas las especies mexicanas forman parte de la sección Vesalea. La filogenia de este grupo fue evaluada mediante un análisis cladístico, utilizando veinte caracteres morfológicos, anatómicos y palinológicos. El estudio incluyó como conjunto interno a todas las especies conocidas de la sección, el externo formado por doce de las asiáticas pertenecientes a las otras secciones del género y como externo funcional a Kolkwitzia amabilis. El análisis apoya la monofília del grupo Vesalea, que está formando un clado hermano de algunas especies de la sección Abelia. La taxonomía de los representantes mexicanos del género comprende cinco especies conocidas y dos variedades que se proponen como nuevas: A. coriacea var. coriacea, A. coriacea var. subcoriacea Villarreal, A. floribunda var. floribunda, A. floribunda var. foliacea Villarreal, A. grandifolia, A. mexicana y A. occidentalis. Se proporciona información relevante sobre la distribución geográfica y los ambientes donde viven cada una de ellas, así como descripciones y una clave para su identificación.

Palabras clave: Abelia, Caprifoliaceae, filogenia, Linnaeaceae, taxonomía. 


\begin{abstract}
The genus Abelia (Caprifoliaceae) includes a set of shrubby plants distributed in the montane temperate regions of eastern Asia and America. The genus is characterized by its persistent sepals, its funnelform or tubular corolla and its indehiscent trilocular capsule. In America all the species known for this genus are restricted to Mexico, and taxonomically they are included in the section Vesalea. A cladistic analysis, using 20 morphological, anatomical, and palynological characters was carried out to evaluate the monophyly of the section Vesalea. All the species of this section were included as the ingroup; in addition, 12 Asiatic abelias pertaining to other sections of the genus were included as outgroup and Kolkwitzia amabilis was used as the functional outgroup. The analysis supports the monophyly of section Vesalea, placed as the sister group of several species of section Abelia. The taxonomy of the Mexican taxa comprises five known species and two new proposed varieties: $A$. coriacea var. coriacea, $A$. coriacea var. subcoriacea Villarreal, $A$. floribunda var. floribunda, A. floribunda var. foliacea Villarreal A. grandifolia, A. mexicana and $A$. occidentalis. Important data on the geographical distribution and the environments where the species occur are provided, as well as descriptions for each one and a key to their identification.
\end{abstract}

Key words: Abelia, Caprifoliaceae, Linnaeaceae, phylogenetic relationships, taxonomy.

\title{
INTRODUCCIÓN
}

Abelia $\mathrm{R}$. Br. es un género ubicado en la familia Caprifoliaceae, caracterizado por su cáliz persistente, sus flores infundibuliformes o tubulares y su fruto seco. Comprende unas 25 especies (sensu lato) o 15-18 (sensu stricto) de arbustos con hojas deciduas (Hutchinson, 1967; Hara, 1983), distribuidas en regiones montañosas templadas y tropicales del hemisferio norte. En México poco se conocía sobre los componentes que lo forman y sus características distintivas. Abelia presenta flores vistosas, lo que ha ocasionado que algunas de sus representantes sean empleadas como ornamentales, de las cuales Bailey (1977) cita cuatro, entre ellas A. floribun$d a$, (M. Martens \& Galeotii) Decne., endémica de México.

Abelia fue propuesto por Robert Brown en 1818, a partir de material recolectado en China. El apelativo del género se designó en honor al doctor Clarke Abel (1780-1826), médico y editor inglés radicado en China y colector de las primeras 
muestras (Coats, 1992). En América fue descrito como Vesalea por M. Martens y H. G. Galeotti en 1844, con la inclusión de dos especies, $V$. floribunda del Pico de Orizaba en Veracruz y $V$. hirsuta del cerro San Felipe en Oaxaca. Dos años más tarde, J. Decaisne (1846) al no hallar diferencias significativas entre Vesalea y Abelia, propuso su fusión bajo el nombre de Abelia, y como nueva combinación a Abelia floribunda, además al no encontrar apropiado el epíteto hirsuta lo sustituyó por el de speciosa, creando así el binomio de $A$. speciosa. Walpers (1846) establece la combinación de Abelia hirsuta. En 1880 W. B. Hemsley describió $A$. coriacea de las montañas del suroeste de San Luis Potosí. V. hirsuta apareció en la sinonimia de $A$. floribunda en la obra de Standley (1926) intitulada Trees and shrubs of Mexico. En una época más reciente, Villarreal (1997) describió $\mathrm{A}$. occidentalis de la región oeste del país y posteriormente a A. grandifolia de Querétaro y A. mexicana de Oaxaca (Villarreal y de la Rosa, 2000). Por lo tanto, el presente trabajo constituye el primer tratamiento taxonómico del género en América en más de 80 años.

La ubicación de Abelia dentro de la familia Caprifoliaceae ha variado. Las clasificaciones de Bentham y Hooker (1873) y la de Hutchinson (1967), lo ubican en la tribu Lonicereae R. Br. ex DC., pero diferentes autores posteriormente lo posicionan en Linnaeae Dumort. (Fritsch, 1902; Fukuoka, 1968; Hara, 1983) o en la familia Linnaeaceae (Backlund y Pyck, 1998). En este trabajo se sigue la propuesta de Cronquist (1981), que lo incluye como parte de Caprifoliaceae.

Abelia también ha estado sujeta a divisiones infragenéricas y a distintas circunscripciones, que incluyen el paso de series a secciones y finalmente la segregación del nuevo género Zabelia (Rehder) Makino (Cuadro 1). De esta forma Hara (1983), siguiendo la clasificación de Fukuoka (1968), propone a Abelia subdividido en dos secciones (Abelia y Vesalea (M. Martens \& Galeotti) Fukuoka), y otras dos (Zabelia Rehder y Biflorae (Zabel) Fukuoka) como integrantes del género Zabelia. La sección Abelia, que incluye a las especies asiáticas, está caracterizada por comprender plantas con cimas de 1-8 flores en grupos axilares o terminales; lóbulos del cáliz 2-5; corola zigomorfa, frecuentemente bilabiada, hinchada en la parte inferior y una glándula nectarífera en forma de almohadilla plana a cortamente clavada, dentro de una protuberancia en la base del tubo de la corola y polen equinulado. La sección Zabelia (Rehder, 1911) o género Zabelia (Fukuoka, 1968 y Hara, 1983) se caracteriza por presentar ramas con seis ranuras longitudinales, nudos engrosados, pecíolos dilatados y connatos en la base, corola con tubo cilíndrico y cuatro a cinco lóbulos extendidos, subiguales y polen con superficie lisa y una banda ecuatorial continua. Finalmente, la sección Vesalea incluye a las especies americanas y se ca- 
Cuadro 1. Ubicación del género Abelia en diferentes propuestas de clasificación.

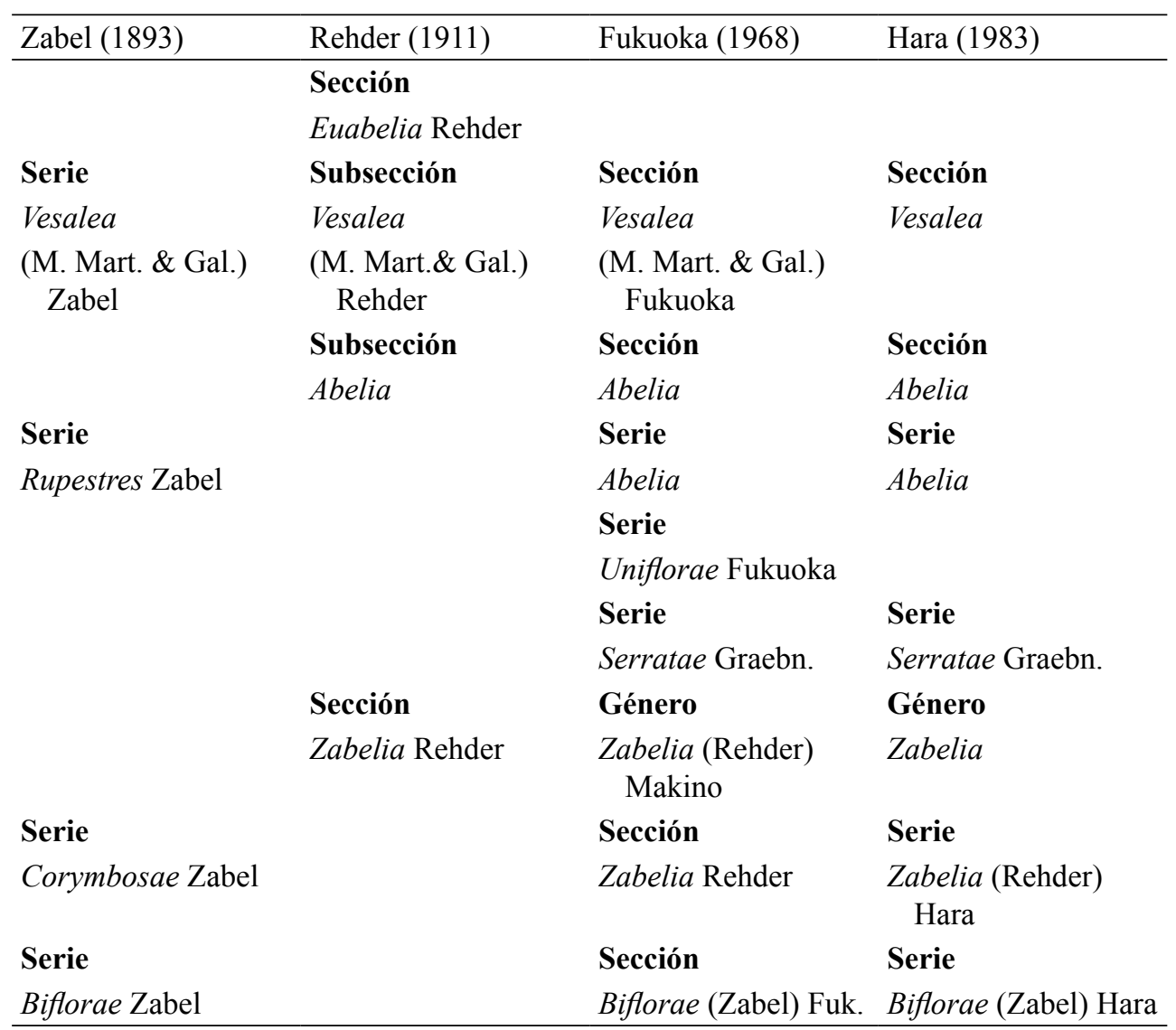

racteriza por poseer racimos terminales con 1-3 flores, cinco lóbulos del cáliz, corola con tubo estrecho y cinco lóbulos subiguales a fuertemente bilabiada, glándulas nectaríferas estrechas en forma de banda (a diferencia de los asiáticos que las tienen en forma de almohadilla albergada en una protuberancia en la base del tubo de la corola) y polen equinulado sin banda ecuatorial.

En la actualidad para la sección Vesalea se reconocen siete taxones, agrupados en cinco especies, todos ellos restringidos a México. Su diferenciación está basada principalmente en caracteres de la hoja, flor y fruto. Incluye a: 1) Abelia coriacea Hemsl., que tiene flores infundibuliformes de 10-16(-24) mm de largo, blanco-rosadas y las hojas enteras con superficie lisa; presenta dos variedades, la típica 
que se conoce de San Luis Potosí y la variedad subcoriacea, propuesta aquí como nueva, con localización en Chihuahua, Coahuila y Nuevo León; 2) Abelia floribun$d a$ (M. Martens \& Galeotti) Decne., que se distingue por las flores tubulares de 30 a $45 \mathrm{~mm}$ de largo, color rojo bermejo y sus hojas usualmente ovadas y serruladas; presenta dos variedades, la típica con repartición en Oaxaca, Puebla y Veracruz y la variedad foliacea, propuesta aquí como nueva, conocida solamente de Chiapas; 3) Abelia grandifolia Villarreal presenta sus hojas elípticas a ovadas, de $18-24 \mathrm{~mm}$ de largo y 9-16 mm de ancho, con venación evidente y superficie abollada y sus flores rosa-lilas, localizada al norte de Querétaro; 4) Abelia mexicana Villarreal, con flores infundibuliformes de 22 a $30 \mathrm{~mm}$ de largo, rosa-lilas, y hojas ovadas a rómbicas con venación evidente, con distribución en Oaxaca y 5) Abelia occidentalis Villarreal se caracteriza por la corola con tubo abruptamente expandido en la parte media, de color rosa-lila y el fruto con un rostro tan largo como la parte ensanchada, propia de Durango y Jalisco.

El énfasis del presente trabajo es taxonómico. Además se evalúa la monofília de la sección Vesalea mediante un análisis cladístico, que permite también explorar sus relaciones filogenéticas.

\section{MATERIALES Y MÉTODOS}

Se revisaron más de 130 ejemplares de herbario, incluyendo los tipos nomenclaturales de cuatro nombres considerados en la historia de la taxonomía del género en México y depositados en ANSM, ASU, BR, CAS, CHAPA, CIIDIR, DS, ENCB, IBUG, IEB, F, K, MEXU, NMC, NY, PH, TEX, UC y XAL. Adicionalmente, con trabajo de campo se procuró visitar el mayor número posible de poblaciones de las diferentes especies; desafortunadamente algunas de ellas no se pudieron evaluar en vivo, debido posiblemente a que ya están extintas o sus poblaciones muy disminuidas y en otros casos por lo inaccesible del lugar.

Para el análisis cladístico se seleccionaron 20 caracteres variables considerados de valor informativo (Cuadro 3), 17 de ellos binarios y tres multiestado con tres estados. Para los rasgos cuantitativos se tomó el promedio de las medidas de 10 muestras tomadas al azar de varios ejemplares para cada taxon. El análisis incluyó 18 especies, cinco de ellas americanas consideradas como el grupo interno y 12 asiáticas de las cuales se dispuso de material de herbario y/o información bibliográfica suficiente para obtener datos comparativos (siete de la sección Abelia y cinco de $\mathrm{Za}$ belia) consideradas como grupo externo (Cuadro 2). Como grupo externo funcional 
Cuadro 2. Especies de Abelia utilizadas en el análisis cladístico, sección a la que pertenecen y su ubicación geográfica.

\begin{tabular}{lll}
\hline Especie & Sección & Ubicación \\
\hline Abelia biflora Turcz. & Zabelia & Asia \\
Abelia buddleioides W. Smith & Zabelia & Asia \\
Abelia chinensis R. Br & Abelia & Asia \\
Abelia dielsii (Graebn.) Rehd. & Zabelia & Asia \\
Abelia integrifolia Koidz. & Zabelia & Asia \\
Abelia macrotera (Graebn. \& Bucw.) Rehd. & Abelia & Asia \\
Abelia parviflora Hemsl. & Abelia & Asia \\
Abelia sanguinea Makino & Abelia & Asia \\
Abelia serrata Sieb. \& Zucc. & Abelia & Asia \\
Abelia spathulata Sieb. \& Zucc. & Abelia & Asia \\
Abelia tetrasepala (Koidz.) Hara \& Kuros. & Abelia & Asia \\
Abelia triflora R. Br. & Zabelia & Asia \\
Abelia coriacea Hemsl. & Vesalea & América (México) \\
Abelia floribunda (Mart. \& Gal.) Dene. & Vesalea & América (México) \\
Abelia grandifolia Villarreal & Vesalea & América (México) \\
Abelia mexicana Villarreal & Vesalea & América (México) \\
Abelia occidentalis Villarreal & Vesalea & América (México) \\
Kolkwitzia amabilis Graebn. & & Asia \\
\hline
\end{tabular}

se utilizó a Kolkwitzia amabilis, la cual se considera estrechamente relacionada con Abelia (Weberling, 1966). La matriz de datos se muestra en el Cuadro 4.

Se llevó a cabo un análisis de parsimonia utilizando el programa Nona (Goloboff, 1997) bajo la plataforma de Winclada (Nixon, 2002). La estrategia de búsqueda se hizo sin constricciones (unconstrained search) utilizando la opción Múltiple TBR+TBR (mult*max*), reteniendo un número máximo de 1000 árboles (hold) con un total de 100 réplicas $(m u l t * N)$ y una cantidad inicial de 10 (hold/).

Para el tratamiento taxonómico se elaboró una descripción morfológica del género seguida de una diagnosis de la sección Vesalea. Se construyó una clave para diferenciar las especies mexicanas y para cada una de ellas se preparó su descripción morfológica, indicando las características distintivas, información de distribución, habitat y ejemplares revisados. Se incluyen además claves para diferenciar variedades. 
Cuadro 3. Caracteres y estados de carácter empleados en el análisis cladístico del género Abelia.

1. Tallos con estrías y nudos engrosados: $0=$ ausente, $1=$ presente.

2. Vestidura del tallo: $0=$ híspida, $1=$ híspidula, $2=$ glabrescente o estrigosa.

3. Forma de la hoja: $0=$ rómbica, 1 = elíptica a ovada.

4. Largo de la hoja: $0=$ más de $18 \mathrm{~mm}, 1=$ menos de $17 \mathrm{~mm}$.

5. Ancho de la hoja: $0=$ más de $15 \mathrm{~mm}, 1=$ menos de $14 \mathrm{~mm}$.

6. Margen de la hoja: $0=$ serrulado, $1=$ entero.

7. Posición de las flores: $0=$ erectas, $1=$ péndulas.

8. Forma de los lóbulos del cáliz: $0=$ elíptica, $1=$ linear a lanceolada.

9. Número de sépalos: $0=$ cinco, $1=$ menos de cinco.

10. Glándula nectarífera en prominencia de la base del tubo de la corola: $0=$ presente, $1=$ ausente.

11. Glándula nectarífera en forma de banda en la corola: $0=$ ausente, $1=$ presente.

12. Número de glándulas nectaríferas en forma de banda en la base del tubo de la corola: $0=1,1=3$.

13. Forma de la corola: $0=$ infundibuliforme, $1=$ tubular.

14. Largo de la corola: $0=$ menos de $2 \mathrm{~cm}, 1=$ más de $2 \mathrm{~cm}$.

15. Color de la corola: $0=$ blanco-amarillo, $1=$ lila, $2=$ rojo.

16. Simetría de la corola: $0=$ bilabiada, $1=$ fuertemente bilabiada, $2=$ subregular.

17. Nivel de inserción de la parte libre de los estambre en la corola: $0=$ garganta, $1=$ porción inferior del tubo.

18. Forma de la base del fruto: $0=$ linear-fusiforme, $1=$ ovada.

19. Disposición de los óvulos: $0=$ pareados, $1=$ solitarios.

20. Polen: $0=$ equinulado, $\sin$ banda ecuatorial, $1=$ liso, con banda ecuatorial.

\section{RESULTADOS}

\section{Análisis cladístico}

El análisis cladístico produjo un solo cladograma más parsimonioso, con una longitud (L) de 55 pasos, un índice de consistencia (IC) de 0.41 y un índice de retención (IR) de 0.62 (Fig. 1). Los resultados del estudio apoyan la monofília de las especies mexicanas, respaldada por tres sinapomorfias (caracteres 10, 11 y 18). La ausencia de una prominencia en la base de la corola para albergar la glándula nectarífera y la presencia de nectarios en forma de banda (caracteres 10 y 11), así como 
Cuadro 4. Matriz de datos utilizada en el análisis cladístico de Abelia.

\begin{tabular}{|c|c|c|c|c|c|c|c|c|c|c|c|c|c|c|c|c|c|c|c|c|}
\hline \multirow[t]{2}{*}{ Especie } & \multicolumn{20}{|c|}{ Carácter } \\
\hline & 1 & 2 & 3 & 4 & 5 & 6 & 7 & 8 & 9 & 10 & 11 & 12 & 13 & 14 & 15 & 16 & 17 & 18 & 19 & 20 \\
\hline Kolkwitzia amabilis & 0 & 0 & 0 & 0 & 0 & 0 & 0 & 0 & 0 & 0 & 0 & $?$ & 0 & 0 & 0 & 0 & 0 & 0 & 0 & 0 \\
\hline Abelia biflora & 1 & 1 & 0 & 0 & 0 & 0 & 0 & 1 & 1 & 0 & 0 & $?$ & 1 & 0 & 0 & 0 & 0 & 0 & 1 & 1 \\
\hline Abelia buddleioides & 1 & 0 & 1 & 0 & 0 & 1 & 0 & 1 & 0 & 0 & 0 & $?$ & 1 & 0 & $?$ & 2 & 0 & 0 & 1 & 1 \\
\hline Abelia chinensis & 0 & 1 & 0 & 0 & 0 & 0 & 0 & 0 & 0 & 0 & 0 & $?$ & 0 & 0 & 0 & 0 & 0 & 0 & 1 & 0 \\
\hline Abelia dielsii & 1 & 0 & 0 & 0 & 0 & 1 & 0 & 0 & 1 & 0 & 0 & $?$ & 1 & 1 & $?$ & 2 & 1 & 0 & 1 & 1 \\
\hline Abelia integrifolia & 1 & 2 & 1 & 0 & 0 & 1 & 0 & 0 & 1 & 0 & 0 & $?$ & 0 & 1 & 0 & 0 & 0 & 0 & 1 & 1 \\
\hline Abelia macrotera & 0 & 0 & 0 & 0 & 0 & 0 & 0 & 0 & 1 & 0 & 0 & $?$ & 0 & 1 & $?$ & 0 & 0 & 0 & 1 & 0 \\
\hline Abelia parviflora & 0 & 0 & 0 & 1 & 1 & 0 & 0 & 0 & 1 & 0 & 0 & $?$ & 0 & 0 & $?$ & 0 & 0 & 0 & 1 & 0 \\
\hline Abelia sanguinea & 0 & 1 & 0 & 0 & 0 & 0 & 1 & 0 & 0 & 0 & 0 & $?$ & 0 & 1 & 2 & 1 & 0 & 0 & 1 & 0 \\
\hline Abelia serrata & 0 & 1 & 0 & 1 & 1 & 0 & 0 & 0 & 0 & 0 & 0 & $?$ & 0 & 0 & 0 & 1 & 0 & 0 & 1 & 0 \\
\hline Abelia spathulata & 0 & 0 & 0 & 0 & 0 & 0 & 1 & 0 & 0 & 0 & 0 & $?$ & 0 & 1 & 0 & 1 & 0 & 0 & 1 & 0 \\
\hline Abelia tetrasepala & 0 & 0 & 0 & 0 & 0 & 0 & 1 & 0 & 1 & 0 & 0 & $?$ & 0 & 1 & 0 & 1 & 0 & 0 & 1 & 0 \\
\hline Abelia triflora & 1 & 0 & 1 & 0 & 0 & 1 & 0 & 1 & 0 & 0 & 0 & $?$ & 0 & 0 & 0 & 0 & 0 & 0 & 1 & 1 \\
\hline Abelia coriacea & 0 & 1 & 1 & 1 & 1 & 1 & 0 & 1 & 0 & 1 & 1 & 0 & 0 & 0 & 0 & 0 & 0 & 1 & 1 & 0 \\
\hline Abelia floribunda & 0 & 1 & 1 & 1 & 1 & 0 & 1 & 0 & 0 & 1 & 1 & 1 & 1 & 1 & 2 & 2 & 1 & 1 & 1 & 0 \\
\hline Abelia grandifolia & 0 & 0 & 1 & 0 & 0 & 0 & 1 & 1 & 0 & 1 & 1 & 0 & 0 & 1 & 0 & 0 & 0 & 1 & 1 & 0 \\
\hline Abelia mexicana & 0 & 0 & 0 & 0 & 0 & 0 & 1 & 1 & 0 & 1 & 1 & 0 & 0 & 1 & 1 & 0 & 0 & 1 & 1 & 0 \\
\hline Abelia occidentalis & 0 & 2 & 1 & 1 & 1 & 0 & 1 & 1 & 0 & 1 & 1 & 0 & 0 & 0 & 0 & 0 & 0 & 1 & 1 & 0 \\
\hline
\end{tabular}

la forma ovada de la base de los frutos (carácter 18) son caracteres únicos para los taxones mexicanos de Abelia y que tienen valor diagnóstico para el reconocimiento de la sección Vesalea. Ésta presenta como grupo hermano a un conjunto de especies de la sección Abelia, que comparten la condición péndula de las flores (carácter 7). Las evidencias a nivel molecular confirman la monofília y también la relación con elementos de la sección Abelia (Jacobs et al., 2010).

Otro conglomerado de especies que se recupera como monofilético es el que constituye a la sección Zabelia (A. biflora, A. buddleioides, A. dielsii, A. integrifolia y A. triflora), ubicado como grupo hermano de un taxon de la sección Abelia (A. macrotera). En estudios de filogenia basados en datos moleculares y morfológicos, se encontró que Zabelia se asocia con otros géneros considerados como externos al conjunto (Jacobs et al., 2010). La distribución de los miembros de la sección Abelia en diferentes clados de la topología, sugieren que la sección, tal y como está actual- 


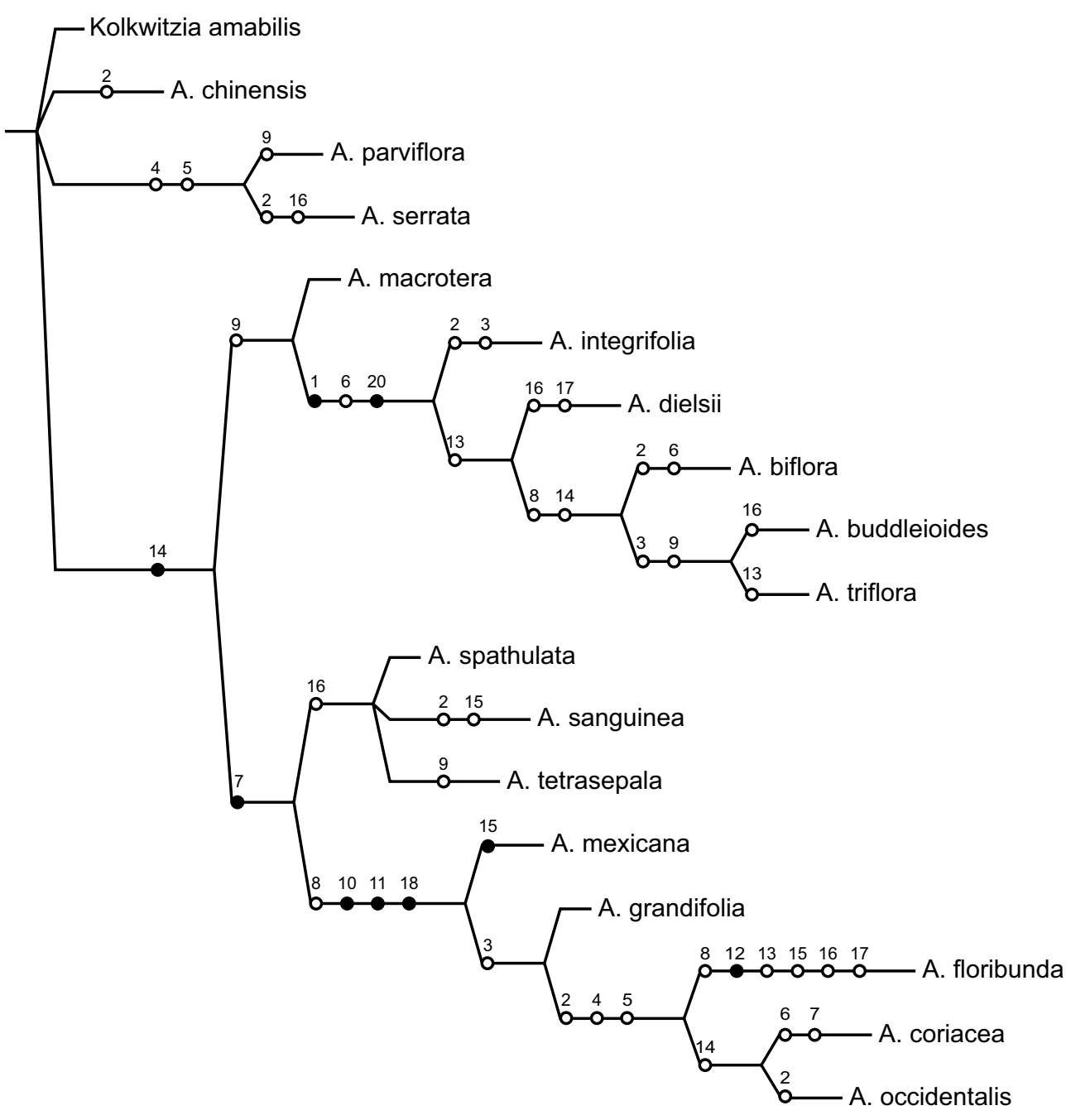

Fig. 1. Cladograma que muestra las relaciones filogenéticas en Abelia $(\mathrm{L}=55, \mathrm{CI}=0.41$, RI $=0.62$ ). Los círculos sólidos indican estados de carácter apomórficos y los círculos abiertos homoplasias. El número sobre las ramas indica el carácter de acuerdo con el Cuadro 3.

mente definida es parafilética, como ha sido discutido previamente por Zhou et al. (2004), Tang y Lu (2005) y más recientemente por Jacobs et al. (2010).

En la sección Vesalea, el taxon que se sitúa como más basal y como grupo hermano de las otras especies es $A$. mexicana, que presenta como autoapomorfia el color lila de la corola y se separa de las demás por las hojas rómbicas (carácter 3). A. grandi- 
folia es a su vez parental de las restantes tres abelias de la sección. Su clado hermano se separa por un conjunto de paralelismos (vestidura del tallo híspidula o estrigosa y el tamaño mayor de las hojas), también observados en elementos asiáticos. Finalmente, este análisis sugiere que $A$. floribunda es el grupo hermano de $A$. coriacea y A. occidentalis; ésta registra como autoapomorfía las tres glándulas nectaríferas en forma de banda en la base del tubo de la corola (carácter 12) y una corola de menor tamaño (carácter 14).

Distribución geográfica y ecológica

El género Abelia presenta una área discontinua, que comprende el este de Asia (China, Japón, Korea y la región de los Himalayas) en el Viejo Mundo y el sur de Norteamérica en el Nuevo Mundo (Good, 1974). En América su presencia se restringe a México. En este país la extensión más norteña la alcanza $A$. coriacea en las montañas del norte de Coahuila y Chihuahua y A. floribunda marca el límite sur en Chiapas, en las proximidades con Guatemala, por lo que no se descarta su presencia en este otro país. Con excepción de $A$. coriacea, que tiene una distribución relativamente amplia, las demás habitan en áreas restringidas, con poblaciones reducidas y muy localizadas.

De acuerdo con observaciones hechas en campo y las obtenidas de los ejemplares de herbario, las especies de Abelia se localizan en diferentes ambientes de la Sierra Madre Occidental, Sierra Madre Oriental, Sierra Madre del Sur y Sierra Madre de Chiapas, con un intervalo altitudinal entre los 1500 y los 2800 m. $A$. coriacea ocupa el mayor número de hábitats, crece en matorrales de encino (chaparrales), matorrales submontanos, matorrales desérticos y bosques de pino-encino. Se asocia con elementos de los géneros Acacia, Agave, Dasylirion, Rhus, Sophora, Vauquelinia y Yucca, entre otros. Abelia floribunda, A. grandifolia, A. mexicana y A. occidentalis crecen en bosques de pino-encino, como parte del estrato arbustivo, donde es frecuente Agave, Juniperus, Rhus y otros. Sólo la población más meridional de A. floribunda es un elemento del bosque mesófilo, donde se presenta Clethra, Magnolia, Oecopetalum y Symplocos.

\section{DISCUSIÓN}

El conjunto de especies mexicanas de Abelia se caracteriza por una ubicación peculiar de los nectarios y la corola sin giba. Otra divergencia morfológica es el ovario ensanchado, que en sus congéneres asiáticos se presenta alargado y estrecho; este cambio influye a su vez en la forma de las semillas, que son ovadas o elípticas y comprimidas, a diferencia de la estructura cilíndrica en las especies de Asia. 
Algunos caracteres vegetativos, tales como el indumento híspido o hispídulo, la forma rómbica, el tamaño mayor y el margen serrulado de la hoja, son considerados plesiomórficos y más frecuentes en elementos asiáticos. Los tallos glabros o estrigosos y las hojas pequeñas con margen entero, son rasgos que se presentan en las especies mexicanas de condiciones menos mésicas.

La condición de flores en posición erecta durante la antesis (carácter 7) es frecuente en las especies asiáticas, mientras que las que se disponen en forma péndula parecen haber evolucionado más de una ocasión e independientemente en diferentes grupos (paralelismos). Los lóbulos del cáliz ensanchados (elípticos) al parecer es la condición plesiomórfica y es común encontrarla en los grupos asiáticos. Los angostos (linear a lanceolados) son comunes en las mexicanas y son considerados como un estado apomórfico. Por otra parte, el presentar cinco lóbulos al parecer es una condición plesiomórfica y su reducción, usualmente por fusión, es considerada como apomorfia. En algunos casos esta condición está dada por eventos de homoplasia, como en éste, con tres paralelismos y dos reversiones.

En el presente estudio se encontró que la forma de la corola no define grupos y la condición plesiomórfica (infundibuliforme) es frecuente en todos los analizados. La forma tubular es la condición considerada apomórfica, aunque con casos de homoplasia entre tres especies del conjunto Zabelia y A. floribunda en México. Para el tamaño (carácter 13), la pequeña (menos de $2 \mathrm{~cm}$ de largo) es un estado de carácter plesiomórfico y la grande (más de $2 \mathrm{~cm}$ de largo) es apomórfico, con paralelismos en $A$. integrifolia, A. macrotera, A. sanguinea, A. spathacea, A. tetrapatera entre las asiáticas y $A$. floribunda, $A$. grandifolia y $A$. mexicana en las mexicanas.

De acuerdo con lo encontrado en este trabajo, el color blanco o rosa de la corola (carácter 15) es una plesiomorfía y se presenta en la mayoría de las especies. Una condición apomórfica es el cambio a rojo, que sólo se observa en A. sanguinea y A. floribunda y todavía un estado más avanzado de este carácter es el lila, el cual es propio de $A$. mexicana. La forma linear a fusiforme de la base del fruto (carácter 18) es recuperada como plesiomórfica y distingue a los grupos asiáticos, mientras que la ovada lo es como apomórfica y distingue al conjunto mexicano.

Fukuoka (1968) consideró a la sección Vesalea (discutiendo solamente a $A$. floribunda) como primitiva, con base en la simetría subregular de la corola y la presencia de tres glándulas nectaríferas lineares. Nuestros resultados (así como los datos moleculares (Jacobs et al., 2010)) no apoyan esta idea, pues la simetría subregular al parecer es una reversión de una condición bilabiada y la disposición de las glándulas es un cambio posterior en la filogenia del género. Además, si consideramos que el mayor número de especies de Abelia se encuentra en Asia, que los gé- 
neros relacionados son básicamente asiáticos y que la mayoría de las caprifoliáceas se localizan en aquel continente, nuestros resultados apoyan una posición derivada del clado Vesalea, el cual se originó de antecesores asiáticos. En esta contribución se reconoce como un carácter plesiomórfico la glándula discoidea, presente en todas las abelias asiáticas, en Kolwitzia y en otros géneros afines. Se considera entonces que las glándulas en banda, características de los miembros mexicanos de Abelia, representan una novedad evolutiva en el grupo.

Con base en lo encontrado en el presente trabajo y estudios relacionados se concluye que Abelia es un taxon formado por tres clados: Zabelia y Vesalea se presentan como monofiléticos, mientras que el de Abelia es parafilético. El clado Vesalea se mantiene siempre relacionado con elementos del grupo Abelia, por lo cual se le considera como una sección del género Abelia. No así Zabelia, que morfológica y molecularmente se aparta del grupo (Jacobs et al., 2010) y puede ser clasificado como un género diferente.

Fitogeografía

$\mathrm{Al}$ igual que otros géneros, Abelia es un ejemplo más de la afinidad florística existente entre los bosques templados de Asia y Norteamérica. El origen de esta repartición disyunta lo revelan las floras fósiles del Cenozoico ampliamente diseminadas en el Hemisferio Norte (Graham, 1972; Wolfe, 1975). Este patrón de distribución muy probablemente es el resultado de los cambios climáticos ocurridos durante el Cenozoico, de la disponibilidad, al menos durante finales del Mioceno, de un puente terrestre entre Asia y Norteamérica y el proceso orogénico que llevó a la formación de grandes cadenas montañosas (Graham, 1972; Tiffney, 1985).

Se postula que la relación entre las masas continentales de América y Asia se debe a la existencia de un extenso espacio de tierra firme que conectó el este de Siberia con Alaska. Esta región, conocida como Beringia, constituyó una ruta de dispersión entre Norteamérica y Eurasia a mediados del Eoceno, hace unos 49 millones de años, con vegetación de bosques deciduos, bosques de coníferas, pastizales y tundra (Sharp, 1966; Raven y Axelrod, 1974). De acuerdo con Graham (1972), para finales del Oligoceno los bosques templados ocupaban grandes áreas de Norteamérica, extendiéndose en el norte hasta el Circulo Ártico, en el este llegando a latitudes templadas de Europa y hacia el oeste a través del puente de tierra de Bering alcanzando Asia. Muchos de los elementos florísticos de aquella época, probablemente el género Abelia entre ellos, ampliaron su área de distribución, que suponemos se originó en Asia (donde tiene actualmente el mayor número de elementos taxonómicos relacionados), incluyendo a Norteamérica como parte de su extensión. Los cambios climáticos 
ocurridos a finales del Terciario (Buchardt, 1978; Collinson et al., 1981) influyeron para que muchas plantas emigraran más al sur, restringieran su distribución a áreas de climas más cálidos dejando poblaciones disyuntas en Norteamérica y Asia, debido a la desaparición de la comunidades naturales en el oeste de Europa por las glaciaciones y el desarrollo de una extensa taiga en las latitudes nórdicas (Graham, 1972).

De manera más particular, la diversificación de las especies mexicanas de Abelia se postula fuertemente asociada a las montañas, por lo que su evolución está relacionada con los procesos de orogénesis. Rzedowski (1978) señala que la distribución de la mayoría de los tipos de vegetación está también íntimamente ligada con este proceso y el vulcanismo en México. Durante el inicio del Eoceno tuvo lugar la orogénesis Hidalgoense, que originó el levantamiento de la Sierra Madre Oriental en el este de México y las Sierras Madres de Oaxaca, Chiapas y Guatemala, lo cual proporcionó áreas apropiadas para Abelia. Más tarde, en el Mioceno-Pleistoceno apareció la Sierra Madre Occidental, con la consecuente formación de extensas zonas áridas en el norte y centro de México (Guzmán y de Cserna, 1963; Ferrusquía, 1993). Dado que el clima posiblemente fue más benigno en aquellas épocas que en la actualidad (Axelrod, 1979), es probable que Abelia extendiera su distribución en las áreas montañosas. A fines del Plioceno y hasta épocas recientes, la actividad volcánica formó el Eje Volcánico Transversal (Guzmán y de Cserna, 1963; Ferrusquía, 1993), lo que dividió a México en las regiones montañosas del norte y del sur. El clima en el Pleistoceno se caracterizó por cambios en temperatura y precipitación, lo cual ocasionó que la vegetación de climas cálidos se desplazara hacia el sur y a regiones más bajas (Rzedowski, 1978; Graham, 1993). La temperatura llegó a ser más baja que la actual en las áreas de terreno caliente de México durante el Pleistoceno, lo que permitió la expansión de bosques templados en áreas de menor elevación y latitud a las conocidas actualmente (Toledo, 1982).

Aunque no se sabe qué tanto descendieron las plantas de regiones altas, es seguro que estuvieron sujetas a ciclos de condiciones secas y húmedas propiciados por períodos glaciares e interglaciares que determinaron los patrones de distribución de los tipos de vegetación (Graham, 1993). Es posible que Abelia expandiera su área, dadas las condiciones climáticas favorables y que posteriormente los cambios en la vegetación, debido a las variaciones climáticas del Pleistoceno, afectaran la extensión del género en América. El aislamiento de poblaciones durante los períodos interglaciares muy posiblemente favoreció la diferenciación y la distribución actual de sus elementos, con la potencial extinción en otras partes de Norteamérica.

Los taxones mexicanos de Abelia muestran un patrón de distribución vicariante. Las poblaciones en la mayoría de los casos, son muy reducidas en la 
actualidad. A. coriacea es la especie con mayor número de localidades conocidas, viviendo en bosques de pino-encino, matorrales submontanos y desérticos.

\section{TRATAMIENTO TAXONÓMICO}

Abelia R. Br., in Abel, Narr. Jour. China App. B. 376. 1818. Vesalea M. Martens \& Galeotti, Bull. Acad. Roy. Sci. Brux. 11(1): 241. 1844. Linnaea L. sect. Abelia (R. Br.) A. Braun \& Vatke. Oesterr., Bot. Zeits. 22: 291. 1872. Linnaea L. subgen. Abelia (R. Br.) Graebn. in Engl. Bot. Jahrb. 29: 125. 1900.

Especie tipo: Abelia chinensis R. Br.

Arbustos muy ramificados; tallos erectos o decumbentes, ramillas rojo-parduscas con vestidura densa de tricomas simples unicelulares, adpresos o extendidos y tricomas glandulares; corteza grisácea, rasgada, delgada, exfoliante (en ocasiones con ranuras longitudinales y nudos engrosados); yemas protegidas por brácteas ovadolanceoladas. Hojas con pecíolos cortos (que pueden presentar las bases dilatadas y connadas), opuestas, usualmente persistentes, elípticas, rómbicas, ovadas a circulares, enteras a serruladas, con los márgenes ligeramente engrosados y con frecuencia ligeramente revolutos, venación reticulódroma, de textura herbácea, coriácea a subcoriácea, con vestidura de tricomas simples y tricomas glandulares (estos últimos a veces sésiles) regularmente distribuida, frecuentemente restringida a la nervadura media y los márgenes, superficie lisa a abollada. Flores 1-2(-8), usualmente pedunculadas, axilares, en las partes terminales de las ramas, involucelo en la base del ovario de cuatro bractéolas pequeñas connadas en la base; cáliz gamosépalo, con (2-)5 lóbulos fusionados brevemente en la base, lineares, lanceolados a elípticos, purpurinos, con indumento parecido al de las hojas, persistentes y ligeramente acrescentes en el fruto; corola infundibuliforme o tubular, el tubo estrecho o ensanchado en la base (en ocasiones con una giba ventral que alberga una glándula nectarífera), el limbo (4-)5-lobular, de ligeramente zigomorfo a bilabiado, indumento externo de abundantes tricomas glandulares, glándula nectarífera en forma de almohadilla o de banda (1 a 3) en la porción inferior de la corola; estambres cuatro, pareados, insertos en el tubo de la corola, ligeramente exertos, anteras dorsifijas, introrsas, alrededor de $2 \mathrm{~mm}$ largo; ovario ínfero, trilocular, estilo largo, ligeramente exerto durante la antesis, estigma ligeramente trilobulado, subcapitado. Fruto una cápsula indehiscente, coronada por el cáliz persistente, trilocular, con dos lóculos estériles y uno fértil; semilla usualmente una, ovada a casi cilíndrica, con superficie finamente coliculada. Número cromosómico básico $\mathrm{x}=8(9)$. 
Sección Vesalea (M. Martens \& Galeotti) Fukuoka, Acta Phytotax. Geobot. 23(3-4): 93. 1968. Vesalea M. Martens \& Galeotti, Bull. Acad. Roy. Sci. Brux. 11(1): 241. 1844. Abelia grupo Vesalea (M. Martens \& Galeotti) Zabel, Mitt. Deuts. Dendr. Ges. 2:33. 1893. Abelia subsect. Vesalea (M. Martens \& Galeotti) Rehder in Sargent, Pl. Wilson. 1:124. 1911.

Especie tipo: Abelia floribunda (M. Martens \& Galeotti) Decne.

Flores (1-)2 en cimas axilares; cáliz de 5 lóbulos; corola infundibuliforme o tubular, sin giba en la base del tubo, lóbulos 5, subregulares a fuertemente bilabiados, glándula nectarífera en 1 o 3 líneas. Fruto con la base ovada; semilla ovada.

Incluye las siguientes especies:

Abelia coriacea Hemsl.

Abelia floribunda (M. Martens \& Galeotti) Decne.

Abelia grandifolia Villarreal

Abelia mexicana Villarreal

Abelia occidentalis Villarreal

Clave para la identificación de las especies mexicanas de Abelia

1. Corola tubular, 30-35(-45) mm largo; lóbulos del cáliz elípticos, 1.5 a $3.0 \mathrm{~mm}$ ancho; glándula nectarífera en tres bandas

A. floribunda

1. Corola infundibuliforme, 10-30(-35) mm largo; lóbulos del cáliz lineares a lanceolados, 0.5 a $1.4 \mathrm{~mm}$ ancho; glándula nectarífera en una banda

2. Tubo de la corola abruptamente ensanchado, la parte estrecha del tubo ocupa

1/2 del largo; hojas elípticas con el ápice obtuso; Dgo. y Jal. .. A. occidentalis

2. Tubo de la corola gradualmente ensanchado, la parte estrecha del tubo ocupa 1/3 del largo; hojas ovadas, circulares a rómbicas, de ser elípticas con el ápice agudo; Chih., Coah., N.L., S.L.P., Qro. y Oax.

3. Tallos decumbentes a postrados; hojas con superficie abollada

A. grandifolia

3. Tallos erectos; hojas con superficie lisa

4. Flores 10-16(-25) mm largo, blanco rosadas; hojas coriáceas a subcoriáceas; Chih., Coah., N.L. y S.L.P. A. coriacea

4. Flores 25-30 mm largo, color lila; hojas membranáceas; Oax. 
Abelia coriacea Hemsl., Diag. P1. Nov. Mex. 3: 53. 1880. TIPO: MÉXICO, San Luis Potosí, chiefly in the region of San Luis Potosí, $22^{\circ} \mathrm{N}, 6000-8000 \mathrm{ft} ., 1878, C$. C. Parry y E. Palmer 299 (holotipo: K; isotipos: F!, NY!).

Arbustos erectos, ramificados, 30-180 cm alto; ramas en plantas xerófilas espinescentes, no punzantes; ramillas rojizas, hispídulas, con tricomas simples, cortos y extendidos, 0.008-0.02 mm de largo y tricomas glandulares. Hojas con pecíolos 0.5-3.2 mm largo, con vestidura hispídula densa; limbos elípticos, ovados a casi circulares, 6-14 mm largo, 3-11 $\mathrm{mm}$ ancho, ápice agudo a obtuso o redondeado, base redondeada, márgenes enteros, ligeramente engrosados, revolutos $\mathrm{y}$ ciliados, venación poco conspicua, textura coriácea a subcoriácea, con abundantes tricomas glandulares cortos (frecuentemente sésiles) y tricomas simples cortos y esparcidos, superficie lisa. Flores axilares en pares, erectas; pedicelos 0.5-1.7 mm largo; involucelo con bractéolas subuladas, alrededor de $0.5 \mathrm{~mm}$ largo; cáliz de cinco lóbulos lineares a lanceolados, 2.5-7.5 mm largo, 0.5-1.4 mm ancho, verde amarillento, con tricomas simples y tricomas glandulares esparcidos; corola infundibuliforme, blanco rosada, tubo con ensanchamiento gradual que ocupa $2 / 3$ del largo, 1.0-2.5 cm largo, ápice del tubo alrededor de $5 \mathrm{~mm}$ ancho, lóbulos 2.4$4.8 \mathrm{~mm}$ largo, con tricomas glandulares y tricomas simples esparcidos, glándula nectarífera en una banda; estambres 4 , insertos en la garganta de la corola, porción libre de los filamentos menor que la porción soldada; estilo $12-22 \mathrm{~mm}$ largo, estigma subcapitado. Fruto alrededor de $4 \mathrm{~mm}$ largo, rostro alrededor de $1 \mathrm{~mm}$ de largo, 5-acostillado, glandular a cortamente hispídulo; semilla 1.4-1.8 mm largo, 0.8-1.2 mm ancho.

Abelia coriacea se caracteriza por sus flores con corolas infundibuliformes, blanco rosadas, de 10-16(-24) mm de largo, sus hojas coriáceas a subcoriáceas, enteras, superficie lisa, con indumento básicamente glandular, con tricomas simples cortos de 80 a $200 \mu \mathrm{m}$ de largo y rostro del fruto alrededor de $1 \mathrm{~mm}$ de largo. Se reconocen dos variedades que se separan por la siguiente clave:

1. Hojas elípticas, con el ápice agudo, venación no evidente; corola 20-24 mm largo; sépalos lanceolados; encinares arbustivos y bosques de pino y encino en suelos derivados de sustrato ígneo; S.L.P. A. coriacea var. coriacea

1. Hojas ovadas a casi circulares, con el ápice obtuso a redondeado, venación evidente; corola 10 -16(-18) mm largo; sépalos lineares; bosque de encinos a matorrales xerófilos en suelos derivados de calizas; N.L., Coah. y Chih. 


\section{Abelia coriacea Hemsl. var. coriacea}

Arbustos erectos, 40-60(-90) cm de alto; hojas elípticas 10-14 mm largo, 4-8 $\mathrm{mm}$ ancho, ápice agudo, base redondeada, margen entero, venación no evidente, coriáceas (0.45-0.55 mm grosor), vestidura de glándulas pediculadas y sésiles y pocos tricomas simples; cáliz con sépalos lanceolados, 3-6 mm largo, 1.0-1.4 mm ancho; corola 20-24 mm largo.

La variedad coriacea está restringida a las montañas cercanas a la ciudad de San Luis Potosí, en encinares arbustivos y pequeños bosques de encino y pino piñonero, en suelos de origen ígneo.

Ejemplares examinados: SAN LUIS POTOSÍ: Mpio. de San Luis Potosí: San Luis Potosí, 1877, J. G. Schaffner 32 (MEXU); San Miguelito, VIII.1879, J. G. Schaffner 485 (CAS, F, MEXU, NY, PH); Sierra San Miguelito, al W de la cañada el Lobo, chaparral de encino, alt. 2300 m, 10.XI.1954, J. Rzedowski 4434 (DS, ENCB, MEXU).

Abelia coriacea Hemsl. var. subcoriacea Villarreal var. nov. TIPO: MÉXICO, Coahuila, Mpio. de Sierra Mojada, Cañón de Hidalgo, Sierra Mojada, above San Salvador Mine, near Esmeralda, along the very steep and difficult trail up the precipitous northern wall of the sierra, 4.VIII.1941, R. M. Stewart 1081 (holotipo: MEXU!; isotipos: ANSM!, F!, TEX!).

Similis Abeliae coriaceae Hemsl. var. coriaceae sed foliis ovatis vel suborbicularibus, subcoriaceis, $6-14 \mathrm{~mm}$ longis, 3-11 mm latis; lobis calycis linearibus; corolla $10-16(-18) \mathrm{mm}$ longa.

Arbustos erectos 30-80(-180) cm alto; hojas ovadas a casi circulares, raramente elípticas, 6-14 mm largo, 3-11 mm de ancho, ápice obtuso a redondeado, base redondeada, margen entero o raramente serrulado, venación evidente, sobre todo en el envés, subcoriáceas (0.35-0.43 mm grosor), vestidura de tricomas simples y tricomas glandulares; cáliz de sépalos lineares, 2.5-7.5 mm largo, 0.5-1.0 mm ancho; corola 10-16(-18) mm largo (Fig. 2).

Abelia coriacea var. subcoriacea se distingue de la variedad típica por sus hojas ovadas a casi circulares, con venación evidente y textura subcoriácea, los lóbulos lineares del cáliz y las corolas más pequeñas de 10-18 $\mathrm{mm}$ de largo (vs. corolas de 20-24 mm de largo).

La nueva variedad se distribuye en la porción terminal de la Sierra Madre Oriental, en la serie de sierras interrumpidas del centro y norte de Nuevo León y Coahuila hasta el noreste de Chihuahua, en suelos derivados de roca caliza (Fig. 3). 
Varía de arbusto de 1 a $1.8 \mathrm{~m}$ de alto, con ramas alargadas y hojas de mayor tamaño, en bosques mesófilos de pino-encino, a arbusto de 30 a $50 \mathrm{~cm}$ de alto con ramas cortas, tendiendo a ser espinescentes y hojas pequeñas, en matorrales xerófilos con Agave lechugilla y Dasylirion cedrosanum, pasando por plantas de porte y características intermedias que se desarrollan en matorrales submontanos.

Ejemplares examinados: CHIHUAHUA: Mpio. de Julimes: Sierra de Carrasco, canyon 31 miles NW of Julimes, 28 ${ }^{\circ} 47^{\prime} \mathrm{N}, 105^{\circ} 09^{\prime} \mathrm{W}$, alt. $6600 \mathrm{ft}, 15 . \mathrm{IX} .1973$, J. Henrickson 12990a (TEX); Mpio. de Ahumada: Sierra de la Alcaparra, 23 miles ENE de Villa Ahumada, 3040' N, $106^{\circ} 07^{\prime}$ W, alt. 5400-5800 ft, 12.IX.1973, J. Henrickson 12830a (TEX); COAHUILA: Mpio. de Acuña: Sierra del Carmen, mina El Popo ca. $2 \mathrm{~km} \mathrm{~S}$ of cañon del Diablo on dissected E slope, $29^{\circ} 12^{\prime} \mathrm{N}, 102^{\circ} 45^{\prime}$ W, alt. 1600 m, 29.VII.1973, M. C. Johnston, T. Wendt y D. Riskind 11919 (ANSM, F, MEXU, NY, TEX); Sierra del Carmen, Mina El Popo, 29¹3' N, 10244' W, alt. $5000 \mathrm{ft}, 29 . \mathrm{VII} .1973$, J. Henrickson 11558 (TEX); SW flank of Sierra del Carmen, $29^{\circ} 06^{\prime} \mathrm{N}, 102^{\circ} 45^{\prime} \mathrm{W}$, alt. $1400 \mathrm{~m}, 15 . \mathrm{IX} .1972$, F. Chiang, M. C. Johnston y T. Wendt 9269 (CAS, MEXU, TEX); Sierra del Carmen, base of cliffs of N side of Pico de Cerda, 29¹2' N, 10249' W, alt. 2100 m, 11.VIII.1974, T. Wendt 567 (MEXU, TEX); Sierra del Carmen, cañón del Diablo, 29¹1' N, 10247' W, alt. 2000 m, 10.VIII.1974, T. Wendt 552 (TEX); Mpio. de Cuatrociénegas: Sierra de la Madera, 2704' N, $102^{\circ} 25^{\prime} \mathrm{W}$, alt. 1700-2000 m, 15.V.1992, M. H. Mayfield, B. G. Milligan y C. McCall1402 (MEXU, TEX); Sierra de La Madera, cañón del Agua, 8.IX.1939, C. H. Muller 3205 (F, TEX, UC); Sierra de La Madera, high crest of main ridge about $2 \mathrm{~km}$ E of Picacho de Zozaya, alt. 8600-8800 ft, 13.IX.1941. I. M. Johnston 9011 (F); Sierra de la Madera, higher part and N slope, $27^{\circ} 02^{\prime} \mathrm{N}, 102^{\circ} 23^{\prime} \mathrm{W}$, alt. 1500$2000 \mathrm{~m}$, 20.IX.1972, F. Chiang, M. C. Johnston y T. Wendt 9402 (CAS, MEXU, NY, TEX); Sierra de La Madera, canyon de La Hacienda, $27^{\circ} 06^{\prime} \mathrm{N}, 102^{\circ} 25^{\prime} \mathrm{W}$, alt. 1500 m, 11.V.1973, M. C. Johnston, F. Chiang y T. Wendt 10984 (CAS, MEXU, NY, TEX); Sierra de la Madera, canyon de la Hacienda, $27^{\circ} 03^{\prime}$ N, $102^{\circ} 24^{\prime}$ W, alt. 8900 ft, 5.VIII.1973, J. Henrickson 11932 (ASU, TEX); Sierra de San Marcos, opposite Los Fresnos, northeast facing slope, D. J. Pinkava, D. Keil, Meyer y Lewis 6127 (TEX); Sierra San Marcos, higher slopes, 264' N, 102 ${ }^{\circ} 05^{\prime} \mathrm{W}$, alt. 1250-1800 m, 9.V.1973, M. C. Johnston, F. Chiang y T. Wendt 10941 (TEX); top of Sierra de San Marcos, NE facing slope, 20.VIII.1968, W. L. Minckley s.n. (ASU, TEX); Mpio. de

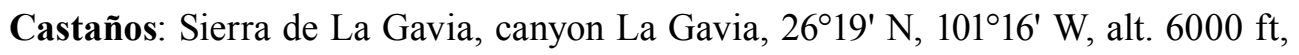
3.VIII.1973, J. Henrickson 11826 (TEX); Mpio. de Ocampo: Sierra de la Madera, $2 \mathrm{~km}$ E of Picacho de Zozaya, alt. 8600-8800 ft, 13.IX.1941, I. M. Johnston 9011 (TEX); Mpio. de Ramos Arizpe: mina El Aguirreño, north side of Sierra de la Pai- 


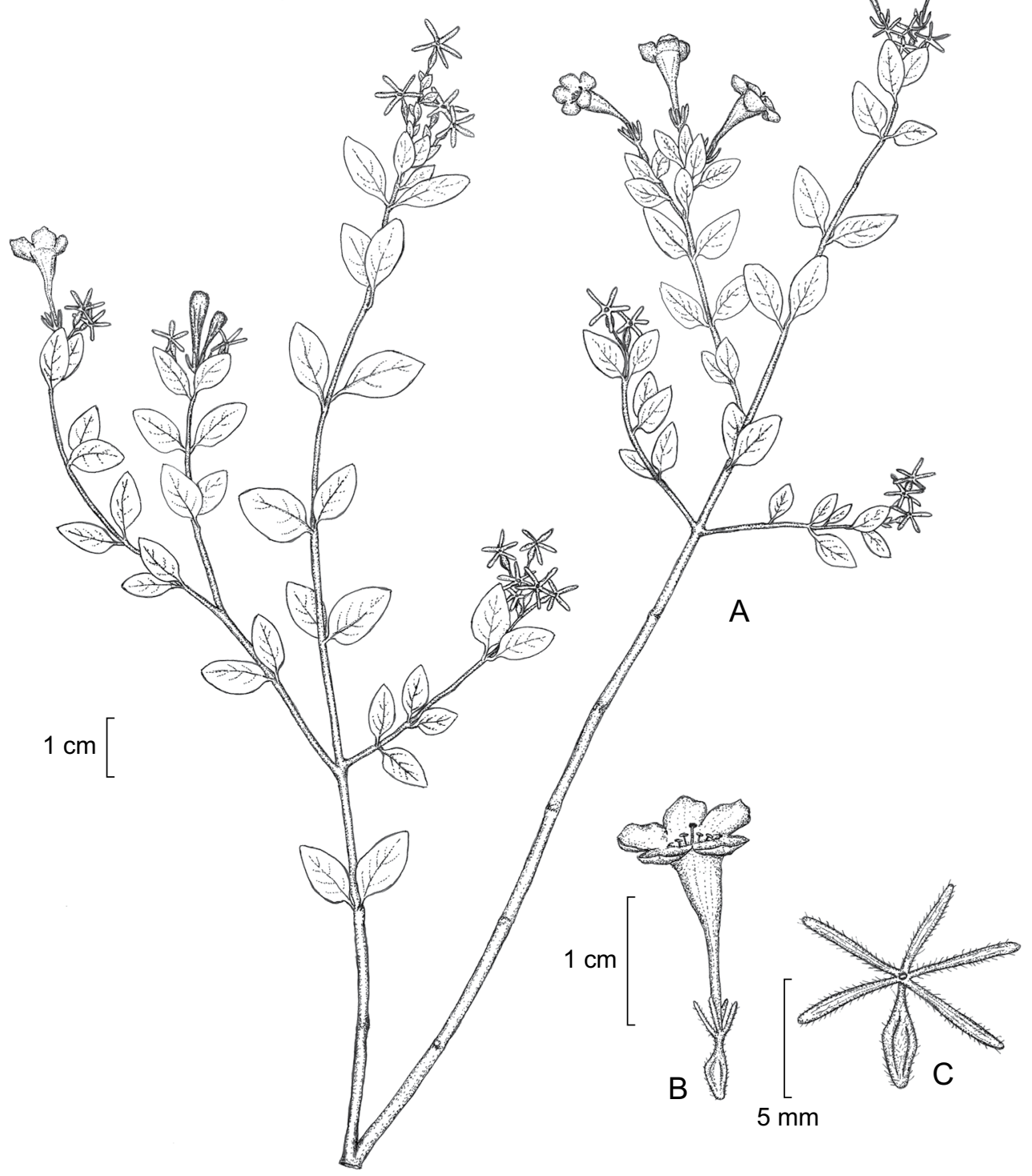

Fig. 2. Abelia coriacea Hemsl. var. subcoriacea Villarreal. A. rama floral; B. flor; C. fruto; (Dibujo basado en R. M. Stewart 1081 (MEXU)). 
la, $26^{\circ} 05^{\prime} \mathrm{N}, 101^{\circ} 36^{\prime} \mathrm{W}$, alt. 1700-2200 m, 5.VII.1973, M. C. Johnston, T. L. Wendt y F. Chiang 11678 (ANSM, CAS, F, NY, TEX); Mpio. de Torreón: Sierra de Jimulco, 6 miles SSW of La Rosita, along trail to the summit, $25^{\circ} 10^{\prime} \mathrm{N}, 103^{\circ} 15^{\prime} \mathrm{W}$, alt. 8200 ft, 18.IX.1973, J. Henrickson 13177 (TEX); NUEVO LEÓN: Mpio. de Galeana: Cerro EL Gallo, oak and Arbutus wood, alt. 2000 m, 23.X.1988, G. B. Hinton 19266 (TEX); Mpio. de Guadalupe: summit of Sierra de la Silla, 7.VI.1889, C. G. Pringle 2546 (F, MEXU, NY, UC); Mpio. de Montemorelos: $6 \mathrm{~km}$ SE of La Trinidad, Sierra La Cebolla, 2511' N, 10007' W, alt. 2100-2500 m, 5.VIII.1988, T. F. Patterson 6100 (TEX); Mpio. de San Pedro Garza García: Chipinque en la Sierra Madre Oriental, limestone cliff, alt. 1500-1700 m, 7.VII. 1934, F. W. Pennell 17251 (F, MEXU, PH); Mpio. de Santiago: Camino entre Laguna de Sánchez y San Isidro, alt. 1500 m, (fr.), 9.X.1991, E. Estrada, C. Schoenfeld, G. Sternberg y J. Fairey 2125 (ANSM); Mpio. de Villaldama: summit of Sierra Gomas in a pine-oak woodland on limestone, $26^{\circ} 20^{\prime} \mathrm{N}, 100^{\circ} 28^{\prime} \mathrm{W}$, alt. $2200 \mathrm{~m}, 15 . \mathrm{VIII} .1988$, T. F. Patterson 6782 (TEX).

Abelia floribunda (M. Martens \& Galeotti) Decne., Fl. Serr. Jard. 2: pl 5. 1846.

Vesalea floribunda M. Martens \& Galeotti, Bull. Acad. Roy. Sci. Brux. 11(1): 242. 1844. Linnaea floribunda (M. Martens \& Galeotti) A. Braun \& Vatke, Osterr. Bot. Zeitschr. 22: 291. 1872. TIPO: MÉXICO, Veracruz, Pico de Orizaba, cordillera de Veracruz, $10000 \mathrm{ft}$., 6.X.1840, H. Galeotti 2641(holotipo: BR!; isotipo: K!). Vesalea hirsuta M. Martens \& Galeotti, Bull. Acad. Roy. Sci. Brux. 11(1): 242. 1844. Abelia speciosa Decne., Fl. Serr. Jard. 2: pl 5. 1846. Abelia hirsuta (M. Martens \& Galeotti) Walp., Repert. Bot. Syst. 6: 3. 1847. TIPO: MÉXICO, Oaxaca, Cerro San Felipe, cordillera oriental de Oaxaca, 7500-9000 ft., 5.IX.1840, H. Galeotti 2640 bis (holotipo: $\mathrm{BR}$ !; isotipo: $\mathrm{K}$ !).

Arbustos erectos, ramificados, $50-150 \mathrm{~cm}$ alto; tallos alargados; ramillas pardo rojizas, hispídulas con tricomas simples $0.010-0.028 \mathrm{~mm}$ largo y tricomas glandulares. Hojas con pecíolos 0.5-3.0 mm largo, hispídulos; limbos oblongos a ovados, (9-)14-20(-25) $\mathrm{mm}$ largo, 5-15 mm ancho, ápice agudo a redondeado, base obtusa a redondeada, márgenes usualmente con 5-6 dientes glandulares tenues por lado, venación evidente, textura herbácea, glabras o con tricomas simples cortos esparcidos, usualmente marginales, superficie lisa. Flores axilares, en pares, colgantes; pedicelos 1-3 mm largo; bractéolas del involucelo subuladas o foliáceas, 0.5-2.0(-7.0) mm largo; cáliz con cinco lóbulos elípticos (frecuentemente dos o tres soldados), 6-11 mm largo, 1.5-3.0 mm ancho, ápice redondeado, verde amarillento 
a purpurino, con abundantes tricomas glandulares cortos y tricomas simples esparcidos; corola tubular, de color rojo púrpura, parte basal del tubo más estrecha, 3-6 $\mathrm{mm}$ de largo, 3-4 $\mathrm{mm}$ de ancho, resto del tubo con ligero ensanchamiento gradual hacia el ápice, 3.0-3.5(-4.5) cm largo 6-12 $\mathrm{mm}$ ancho en el limbo, lóbulos 4-7 mm largo, externamente hirsútula y con tricomas glandulares, internamente hirsuta en la porción inferior del tubo, glándula nectarífera en tres bandas; estambres 4, filamentos insertos en la porción inferior del tubo de la corola, su parte libre más larga que la porción soldada; estilo 3.5-4.6 mm largo, estigma subcapitado. Fruto 3.6-5.2 $\mathrm{mm}$ largo, rostro 0.8-2.0 $\mathrm{mm}$ largo, hispídulo glandular, cáliz persistente y ligeramente acrescente, de color púrpura; semilla 2.2-3.0 mm largo, 1.8-2.4 $\mathrm{mm}$ ancho. Número cromosómico $n=16$.

Abelia floribunda se distingue fácilmente por sus flores tubulares, colgantes, de 30 a $45 \mathrm{~mm}$ de largo, color rojo bermejo, pedicelos de 1 a $3 \mathrm{~mm}$ de largo, lóbulos del cáliz elípticos, algunos de ellos frecuentemente fusionados, hojas usualmente ovadas, de textura herbácea, con margen serrulado. La especie se distribuye principalmente en las montañas de Oaxaca y Chiapas, en bosque de pino-encino (Fig. 3).

Se reconocen dos variedades, las cuales se separan por la siguiente clave:

1. Bractéolas del involucelo subuladas, 0.5-2.0 $\mathrm{mm}$ largo, 0.3-0.6 $\mathrm{mm}$ ancho; hojas con limbo liso; Pue., Ver., Oax. ............................ A. floribunda var. floribunda

1. Bractéolas del involucelo obovadas, 3-7 mm largo, 1.5-4 mm ancho; hojas con limbo abollado; Chis. A. floribunda var. foliacea

Abelia floribunda (M. Martens \& Galeotti) Decne. var. floribunda.

Arbustos erectos 50-150 cm alto. Hojas ovadas, 12-25 mm largo, 6-15 mm ancho, ápice obtuso, raramente redondeado, base redondeada, margen serrulado, raramente entero, venación evidente, vestidura de tricomas simples y glandulares, superficie lisa. Flores con bractéolas del involucelo subuladas, 0.5-2.0 mm largo, 0.3-0.6 mm ancho: cáliz con lóbulos elípticos, 6-12 mm largo, 1.5-3.0 mm ancho; corola 30-45 mm largo, de color rojo bermejo. Fruto 3.6-5.2 mm largo, rostro 0.8-2.0 $\mathrm{mm}$ largo, hispídulo-glandular, cáliz en el fruto de color púrpura.

Abelia floribunda var. floribunda tiene hojas ovadas, con venación evidente en una superficie lisa y las bractéolas del involucelo subuladas, 0.5-2.0 mm largo y 0.3-0.6 mm ancho. La amplia variación en las dimensiones de las hojas y flores 
se relaciona con el hábitat. Bosques de pino-encino. Especímenes de lugares menos húmedos muestran hojas y flores más pequeñas.

Ejemplares examinados: OAXACA: Mpio. de Santa Catarina Zapoquila: cerro el Chicamole, cañada al $\mathrm{W}$ de Guadalupe Membrillos, camino al arco, $18^{\circ} 02^{\prime}$ N, 97³3' W, alt. 2100 m, 14.IX.1991, P. Tenorio 17477 (CAS, F, MEXU); Mpio. San Miguel Amatlán: $18 \mathrm{~km}$ al $\mathrm{N}$ de Díaz Ordaz, por la desviación a Cuajimoloyas, bosque de pino-encino, $17^{\circ} 06^{\prime} \mathrm{N}, 9^{\circ} 27^{\prime} \mathrm{W}$, alt. $2730 \mathrm{~m}, 14 . \mathrm{V} .1983, R$. Torres, $P$. Tenorio, L. Romero 2836 (MEXU); $18 \mathrm{~km}$ al N de Díaz Ordaz, por la desviación a Cuajimoloyas, bosque de pino-encino, $17^{\circ} 06^{\prime} \mathrm{N}, 96^{\circ} 27^{\prime} \mathrm{W}$, alt. $2700 \mathrm{~m}$, 8.IX.1995, J. Á. Villarreal, J. Panero y J. L. Villaseñor 8225 (ANSM); $18 \mathrm{~km}$ al $\mathrm{N}$ de Díaz Ordaz, por la desviación a Cuajimoloyas, bosque de pino-encino, $17^{\circ} 06^{\prime} \mathrm{N}, 96^{\circ} 27^{\prime} \mathrm{W}$, alt. 2700 m, 17.VIII.1997, J. Á. Villarreal y J. I. Calzada 8602 (ANSM); Mpio. de Oaxaca: vicinity of Cerro San Felipe, alt. 9500-11000 ft., 1897, E. W. Nelson 1053 (MEXU); Sierra San Felipe, dry ledges, alt. 8000-10000 ft., 5.IX.1894, C. G. Pringle 4649 (F, MEXU, NY, PH, UC); Cerro de San Felipe, 12.II.1937, W. H. Camp 2598 (NY); Cerro San Felipe, alt. 8500-9000 ft, 2.II.1975, S. Walker $75 H 35$ (NY); Sierra de San Felipe, alt. 10000 ft, 28.VIII.1894, C. L. Smith 852 (F); PUEBLA: Mpio. de Palmar de Bravo: Cerro Tepoxtla (Filo de la Tierra Colorada), San Martín Esperilla, $300 \mathrm{~m}$ al E de la mina de cantera, matorral de Dasylirion, Quercus, Agave, Yucca, Arbutus, Rhus, 1844' N, 97³3' W, alt. 2700 m, 31.X.1991, P. Tenorio, P. Dávila y J. Panero 17984 (MEXU); alt. 2500 m, 5.V.1992, P. Tenorio 18295 (MEXU); Cerro Tepoxtla (Filo de la Tierra Colorada), San Martín Esperilla, $300 \mathrm{~m}$ al E de la mina de cantera, alt. 2580 m, 7.IX.1995, J. Á. Villarreal, J. Panero y J. L. Villaseñor 8223 (ANSM); Mpio. de Tehuacán: Cerro de Paxtle, VII.1907, C. A. Purpus 2554 (UC); Mpio. de Caltepec (San Luis Atolotitlán): VII.1908, C. A. Purpus 2554a (F, NY, UC); Tlacuilotepec, VIII.1909, C. A. Purpus 3983 (UC); VERACRUZ: Mpio de Perote: cerros calizos al S en la carretera a Xalapa entre Alchichica y Totalco, C. Ramos 293 (MEXU); Mpio. de Calcahualco: Pico de Orizaba, Barranca de San Miguel Tlaquiotiopa, bosque de pino-encino, alt. $2550 \mathrm{~m}, 2 . V I I .1985$, M. Cházaro y M. Leach 3453 (XAL); Mpio. de Tonayán: Sierra La Magdalena, bosque de pinoencino, alt. 2450 m, 10.VI.1981, M. Cházaro 1550 (F, XAL).

Abelia floribunda (M. Martens \& Galeotti) Decne. var. foliacea Villarreal var. nov. TIPO: MÉXICO, Chiapas, Mpio. de Motozintla, southwest side of cerro Mozotal, $11 \mathrm{~km}$ northwest of the junction of the road to Motozintla, along the road to El Porvenir and Siltepec, montane rain forest, alt. $2100 \mathrm{~m}$, 19.XI.1971, D. E. Breedlove y A. R. Smith 22838 (holotipo: DS!). 
Similis Abeliae floribundae var. floribundae sed foliis ellipticis, lamina bullata conspicue serrulata, 9-18 $\mathrm{mm}$ longa, 5-8 $\mathrm{mm}$ lata; bracteis ab involucello foliaceis obovatis, 3-7 mm longis, $1.5-4 \mathrm{~mm}$ latis.

Arbustos erectos 40-90(-180) cm alto. Hojas oblongas a elípticas, 9-18 mm largo, 5-8 $\mathrm{mm}$ ancho, ápice obtuso a redondeado, base redondeada, margen conspicuamente serrulado y glandular, venación evidente, sobre todo en el envés, superficie abollada, vestidura de tricomas simples y glandulares. Flores con bractéolas del involucelo obovadas, 3-7 mm largo, 1.5-4 mm ancho; cáliz con lóbulos elípticos, 6-9 $\mathrm{mm}$ largo, 1.5-3.0 mm ancho; corola 28-35 mm largo, de color rojo. Fruto 3.5-5.0 mm largo, rostro 0.8-1.8 $\mathrm{mm}$ largo, híspidulo-glandular.

Abelia floribunda var. foliacea se distingue de la variedad típica por sus hojas oblongas a elípticas, con venación evidente y superficie abollada y las bractéolas del involucelo más grandes, obovadas, foliáceas, de 3-7 mm largo y 1.5-4 mm de ancho.

La nueva variedad se distribuye en la porción oeste de la Sierra Madre de Chiapas, cerca de los límites con Guatemala (Fig. 3). Actualmente sólo es conocida de la localidad tipo. Crece en bosque con Oecopetalum, Magnolia, Clethra, Pinus, Quercus y Symplocos.

Ejemplares examinados: CHIAPAS: Mpio. de Motozintla: southwest side of Cerro Mozotal, $11 \mathrm{~km}$ northwest of the junction of the road to Motozintla, along the road to El Porvenir and Siltepec, montane rain forest, alt. $2100 \mathrm{~m}, 27 . \mathrm{VI} .1972, D$. E. Breedlove 25909 (DS); southwest side of cerro Mozotal, $11 \mathrm{~km}$ northwest of the junction of the road to Motozintla, along the road to El Porvenir and Siltepec, montane rain forest, alt. $2100 \mathrm{~m}$, 29.XII.1972, D. E. Breedlove y R. F. Thorne 31113 (CAS).

Abelia grandifolia Villarreal, Brittonia 52(2): 174. 2000. TIPO: MÉXICO, Querétaro, Mpio. de Jalpan, 9-10 km al S de San Juan de los Durán, Cerro Grande, laderas de bosque de pino-encino, alt. 2600-2700 m, 13.VI.1991, B. Servín 1101 (holotipo: IEB!; isotipo: CAS).

Arbustos decumbentes a postrados, $60-150 \mathrm{~cm}$ largo; ramillas pardo rojizas, engrosadas, 1.0-1.5 mm de ancho, híspidas, con abundantes tricomas simples 0.040$0.055 \mathrm{~mm}$ largo y tricomas glandulares. Hojas con pecíolos 3.2-5.0 mm largo, híspidos; limbos elípticos a ovados, 18-25 mm largo, 9-16 $\mathrm{mm}$ ancho, ápice agudo a redondeado, base redondeada, márgenes crenulados, venación conspicua, textura subcoriácea, vestidura hispídula de tricomas simples de hasta $600 \mu \mathrm{m}$ largo, abundantes en las venas del envés, superficie abollada. Flores axilares, colgantes, en la porción terminal de los tallos; pedicelos 1.2-2.8 mm largo; bractéolas del involucelo 
lineares, 1.5-3.0 mm largo; cáliz con lóbulos linear lanceolados, 4.8-6.5 mm largo, 0.6-1.2 $\mathrm{mm}$ ancho, verde amarillentos, con tricomas glandulares cortos y tricomas simples marginales; corola infundibuliforme, de color rosa lila, tubo con ensanchamiento gradual que ocupa 2/3 de su largo, 2.0-2.8 cm largo, ápice del tubo 10.2-11.6 $\mathrm{mm}$ ancho, lóbulos 4.4-5.2 mm largo, con tricomas glandulares y tricomas simples esparcidos, glándula nectarífera en una banda; estambres 4, insertos en la garganta de la corola, porción libre de los filamentos más corta que la soldada; estilo 2.0-3.0 cm largo, estigma subcapitado. Fruto 3.8-4.4 mm largo, rostro 1.0-1.8 mm largo, híspido; semilla 2.0-2.6 mm largo, 1.0-1.6 mm ancho. Número cromosómico $n=16$.

A. grandifolia se caracteriza por sus tallos decumbentes a postrados, las hojas elípticas a ovadas de textura subcoriácea, 18-24 mm de largo y 9-16 $\mathrm{mm}$ de ancho, con venación evidente y superficie abollada entre las venas, y sus flores rosa lilas. Crece en afloramientos rocosos, en bosques de pino-encino-cedro, asociada con Amelanchier, Agave, Salvia y Dodonaea, entre otras.

Sólo se ha colectado en la región norte del estado de Querétaro (Fig. 3).

Ejemplares examinados: QUERÉTARO: Mpio. de Jalpan: 6-7 km al NE de la Lagunita de San Diego, vertiente SE del Cerro Grande, alt. 2250-2300 m, 20.X.1996, E. Pérez y E. Carranza 3520 (ANSM, IEB); Mpio. de Landa: Las Abras del Cerro Grande, al NE de la Lagunita de San Diego, bosque de encino, ladera de cerro, 27.X.1990, E. Carranza 2876 (IEB); 7-8 km al NE de Lagunita de San Diego, ciénega del Cerro Grande, bosque de pino, encino y cupresos, ladera de cerro, alt. 2060 m, 28.VIII.1991, B. Servín 1299 (IEB); cerca de $3.5 \mathrm{~km}$ al E-NE de la Lagunita de San Diego, $21^{\circ} 23^{\prime}$ N, $99^{\circ} 08^{\prime}$ W, bosque de pino, encino y enebro, 2.X.1997, E. Carranza, E. Pérez y J. Á. Villarreal 5388 (IEB).

Abelia mexicana Villarreal, Brittonia 52(2): 172. 2000. TIPO: MÉXICO, Oaxaca, Mpio. San Sebastián Tecomaxtlahuaca, cerca de $10 \mathrm{~km}$ de San Sebastián Tecomaxtlahuaca, camino a San Martín Duraznos, $17^{\circ} 18^{\prime}$ N, $98^{\circ} 06^{\prime} \mathrm{W}$, bosque de Quercus-Juniperus-Brahea, alt. 1755 m, 19.VII.1996, J. I. Calzada 21100 (holotipo: MEXU!, isotipos: ANSM!, ENCB!)

Arbustos erectos, ramificados, $60-150 \mathrm{~cm}$ alto, con ramas alargadas; ramillas parduscas, híspidas, con abundantes tricomas simples 0.04-0.06 mm largo y tricomas glandulares. Hojas con pecíolos 2.2-3.4 mm largo, híspidos; limbos elípticos a rómbicos, $18-23 \mathrm{~mm}$ largo, $8-13 \mathrm{~mm}$ ancho, base aguda a cuneada, ápice agudo a obtuso, márgenes serrulados con 5-6 dientes glandulares por lado, venación evidente, textura herbácea, haz glabro o con vestidura híspidula, envés híspido 
con abundantes tricomas simples de hasta $800 \mu \mathrm{m}$ largo en la vena central y venas secundarias, superficie lisa. Flores axilares, colgantes, en la porción terminal de los tallos; pedicelos cortos, 0.8-2.2 mm largo, híspidos; bractéolas del involucelo lineares, 0.8-2.4 mm largo; cáliz con lóbulos linear-lanceolados, 5.0-7.0 mm largo, 0.6-1.4 mm ancho, ápice agudo, verde amarillento, con tricomas glandulares cortos y tricomas simples marginales; corola infundibuliforme, de color rosa lila, tubo con ensanchamiento gradual que ocupa $2 / 3$ de su largo, 2.2-3.0 cm largo, ápice del tubo 7.8-9.6 mm ancho, lóbulos 4.6-6.0 mm largo, con tricomas glandulares y tricomas simples esparcidos, glándula nectarífera en una banda; estambres 4 , insertos en la garganta de la corola, porción libre de los filamentos más corta que la soldada; estilo 2.0-3.0 cm largo, estigma subcapitado. Fruto 3.8-4.6 mm largo, rostro 0.8-1.8 mm de largo, híspido, cáliz ligeramente acrescente, de color verde amarillento; semilla 2.0-2.6 mm largo, 0.8-1.6 mm ancho. Número cromosómico $n=16$.

Abelia mexicana presenta corola infundibuliforme con un tubo gradualmente ensanchado hacia el ápice y lóbulos linear-lanceolados en el cáliz. Difiere de A. coriacea por sus flores de mayor tamaño, 2.2 a $3.0 \mathrm{~cm}$ de largo (no 1.0 a $1.6 \mathrm{~cm}$ ), de color rosa-lila (no blanco-rosado), hojas ovadas a rómbicas de 1.8 a $2.3 \mathrm{~cm}$ largo, con nervación evidente, margen serrulado glandular, vestidura híspida de tricomas simples, al menos a lo largo de la nervadura principal (contra hojas ovadas a elípticas de 0.6 a $1.4 \mathrm{~cm}$ largo, con venación poco evidente, margen entero y con vestidura hispídula).

Las hojas con indumento híspido en la venación del envés con tricomas simples extendidos, de $530 \mu \mathrm{m}$ de largo en promedio constituyen el rasgo vegetativo más sobresaliente de esta especie. Esto la distingue del resto de los elementos americanos conocidos, los cuales tienen tricomas cortos e incurvados; sin embargo, es frecuente en muchos de los asiáticos. Aunque el carácter de la hoja es compartido por esta especie en América y representantes de Asia, los florales las separan.

Ejemplares examinados: OAXACA: Mpio. de Putla de Guerrero: Slope with Pinus and Quercus, $52 \mathrm{~km} \mathrm{~W}$ of Tlaxiaco on road to Putla, alt. $2375 \mathrm{~m}, 26 . V I I I .1988$, D. E. Breedlove 69627 (CAS, TEX); Mpio. de Tlaxiaco: Slope with Pinus and Quercus, $10 \mathrm{~km}$ NE of Chicahuaxtla, alt. $2130 \mathrm{~m}, 26 . X .1991, D$. E. Breedlove y D. Mahoney 72232 (CAS); $26 \mathrm{~km}$ al NE de la desviación a Tlaxiaco, carr. Putla - Tlaxiaco, bosque mesófilo, alt. $2330 \mathrm{~m}, 10 . \mathrm{VIII} .1985, R$. Torres, L. Torres y C. Martínez 7249 (CAS); Mpio. San Pedro Mixtepec: Steep slope above Río San Pedro, 21.XII.1951, T. MacDougall s.n. (NY); Mpio. de San Sebastián Tecomaxtlahuaca: Cerca de

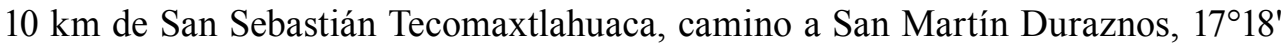
N, 9806' W, bosque de Quercus-Juniperus-Brahea, alt. 1755 m, 17.VIII.1997, J. Á. Villarreal y J. I. Calzada 8601 (ANSM, MEXU). 
Abelia occidentalis Villarreal, Brittonia 49(1): 84. 1997. TIPO: MÉXICO, Durango, Mpio. de Súchil, estación La Michilía, $23^{\circ} 27^{\prime} \mathrm{N}, 104^{\circ} 18^{\prime} \mathrm{W}$, alt. $2580 \mathrm{~m}$, 27.VIII.1995, J. Á. Villarreal, M. A. Carranza y A. García 8180 (holotipo: MEXU!; isotipos: ANSM!, CIIDIR!, ENCB!, TEX!).

Arbustos erectos muy ramificados, 40-50(-60) cm alto; ramillas rojizas con vestidura estrigosa de tricomas simples, curvos, antrorsos, 0.02-0.04 $\mu \mathrm{m}$ largo, $\mathrm{y}$ tricomas glandulares esparcidos. Hojas con pecíolos 0.5-1.5 mm largo, estrigosos; limbos elípticos, 10-19 mm largo, 2-8 mm ancho, ápice obtuso, base aguda, márgenes enteros a serrulados, venación conspicua, textura herbácea, vestidura ausente a estrigosa, de tricomas simples esparcidos, usualmente concentrados en la nervadura media, superficie lisa. Flores axilares, colgantes; pedicelos 0.2-0.9 $\mathrm{mm}$ largo, hispídulos; bractéolas del involucelo lineares, 0.5-2.0 mm largo; cáliz con lóbulos linear lanceolados, 5.0-7.5 mm largo, 0.5-1.2 $\mathrm{mm}$ ancho, verde amarillento, con tricomas glandulares cortos y tricomas simples marginales; corola infundibuliforme, rosada, tubo abruptamente ensanchado en la porción media, 2.2-3.5 cm largo, la parte estrecha ocupa 1/2 de su largo, ápice del tubo 6.2-11.5 $\mathrm{mm}$ ancho, lóbulos 4.2-6.2 mm largo, con tricomas glandulares y tricomas simples esparcidos, glándula nectarífera en una banda; estambres 4, insertos en la garganta de la corola, porción libre de los filamentos más corta que la soldada; estilo 2.0-3.5 cm largo, estigma subcapitado. Fruto 4.8-5.8 mm largo, rostro 1.8-3.0 mm de largo, híspidulo; semilla elíptico obovada, 2.0-2.6 mm largo, 1.0-1.4 mm ancho. Número cromosómico $n=16$.

Abelia occidentalis se caracteriza por su corola de 2.2-3.5 $\mathrm{mm}$ de largo, de color rosa, su tubo abruptamente expandido en la porción media, sus hojas elípticas (2:1 a 3:1), de textura herbácea, superficie lisa, rostro del fruto tan largo como la parte ensanchada y el indumento del tallo y ramillas estrigoso, con tricomas cortos, curvados antrorsamente. Este último carácter sólo se ha observado al parecer en esta especie americana, y es frecuente en las asiáticas (Hara, 1983).

Los especimenes de Jalisco, que representan la población más meridional, tienen limbos de las hojas más bien rómbicos con abundantes tricomas simples y glandulares.

La especie se conoce de la Sierra Madre Occidental, de un área en el sureste de Durango y otra en el norte de Jalisco (Fig. 3), donde crece como arbusto en laderas y a la orilla de arroyos, en bosques de pino-encino extendiéndose hasta lugares abiertos más xéricos. El área de distribución muy probablemente alcance los estados de Zacatecas y Nayarit. 
Ejemplares examinados: DURANGO: Mpio. de Súchil: Reserva de la Michilía, Ciénega Los Caballos, Bosque de pino-encino, alt. 2570 m, 25.XI.1985, S. González y J. Rzedowski 3723 (ANSM, CIIDIR, IEB); Reserva de la Michilía, Ciénega Los Caballos, Bosque de pino-encino, alt. 2570 m, 9.IX.1996, A. García 2406 (ANSM); Reserva de la Michilía, entre El Taray y ciénega de Los Caballos, bosque de Pinus lumholtzii y Quercus, alt. 2540 m, 18.VI.1986, S. González 3804 (ANSM, CIIDIR, IEB, NMC, TEX); Ciénega de Los Caballos, 2320' N, 104¹7' W, 10.VI.1977, E.

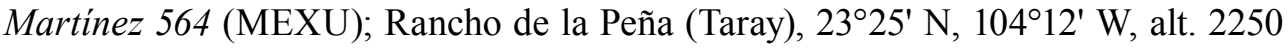
m, 9.VI.1976, E. Martínez 531 (MEXU); Magueicitos, reserva La Michilía, bosque de encino-pino, VI.1975, S. Gallina, E. Murray y V. Serrano 34 (IEB); JALISCO: Mpio. de Bolaños: $14 \mathrm{~km}$ al NW de Bolaños, por la brecha a los Amoles, sobre cañada húmeda, en un arroyo, bosque de pino-encino, alt. $1600 \mathrm{~m}, 8 . \mathrm{VIII} .1986, F$. $J$. Santana et al. 1743 (IBUG, MEXU); La Toma, cerca de $20 \mathrm{~km}$ al NW de Bolaños, por la brecha a Bolaños, bosque de pino-encino, alt. 2200 m, 16.VI.1990, A. Flores M., G. Martínez P. y N. P. Ramos G. 1880 (MEXU).

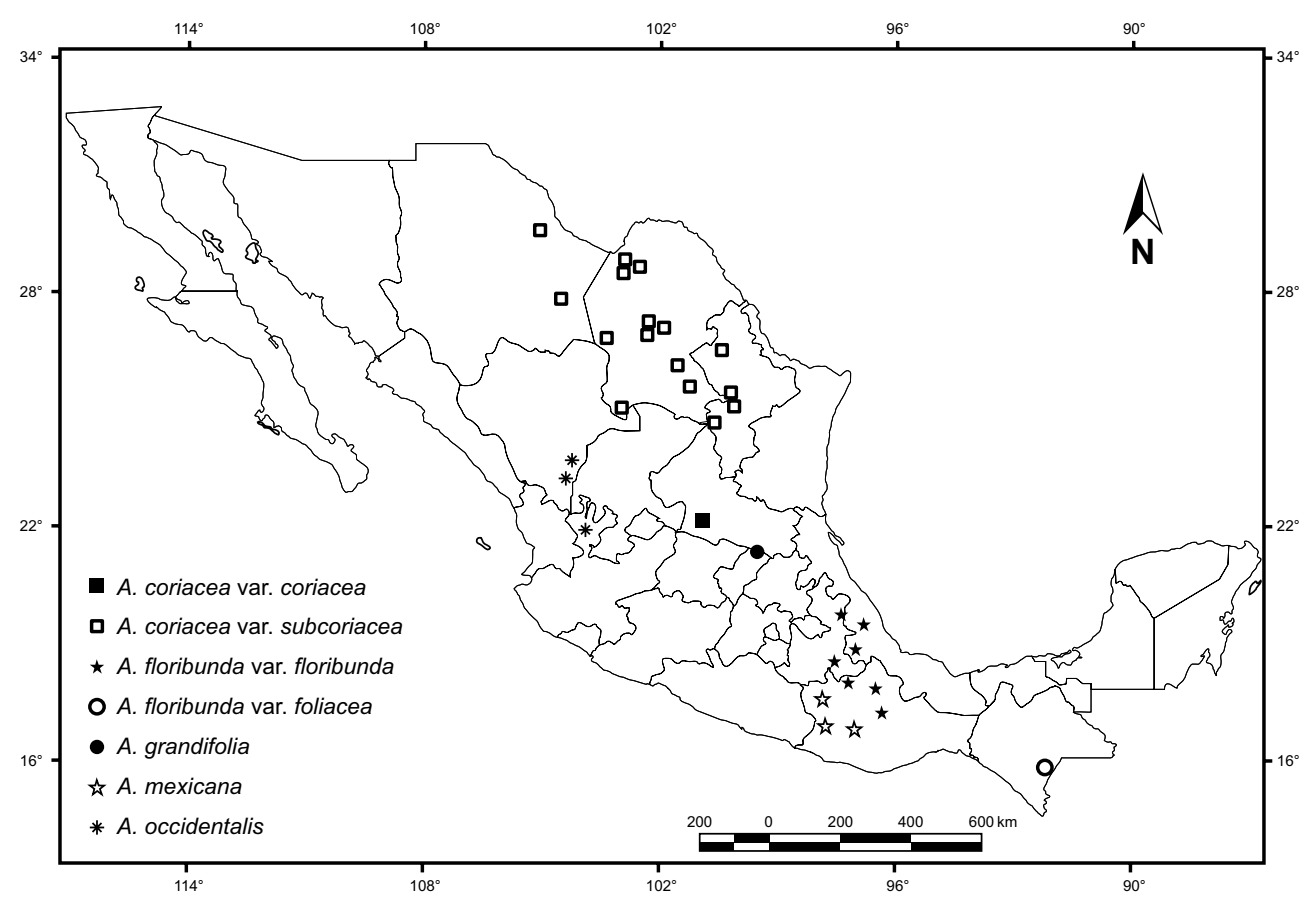

Fig. 3. Distribución geográfica de las especies de Abelia en México. 


\section{AGRADECIMIENTOS}

Se agradece el apoyo brindado por el posgrado de la Facultad de Ciencias y el Instituto de Biología de la Universidad Nacional Autónoma de México, y al Consejo Nacional de Ciencia y Tecnología por la ayuda financiera para la realización de la tesis de doctorado del primer autor, de la cual deriva este trabajo. A Rosario Redonda-Martínez por su ayuda en la realización del análisis cladístico. A José Ismael Calzada, Eleazar Carranza, Abel García y José Panero por su apoyo en el trabajo de campo.

\section{LITERATURA CITADA}

Axelrod, D. I. 1979. Age and origin of Sonoran Desert vegetation. Occas. Pap. Calif. Acad. Sci. 132: 1-87.

Backlund, A. y N. Pyck. 1998. Diervillaceae and Linnaeaceae, two new families of caprifolioids. Taxon 47(3): 657-661.

Bailey, L. H. 1977. Manual of cultivated plants. McMillan Publ. Co. Inc. New York, USA.1116 pp.

Bentham G. y J. D. Hooker. 1873. Genera plantarum. Vol. 2. Levell Reeve \& Co. London, UK. 1279 pp.

Buchardt, B. 1978. Oxygen isotope paleotemperatures from the Tertiary period in the North Sea area. Nature 275: 121-123.

Coats, A. M. 1992. Garden shrubs and their histories. Simon and Schuster. New York, USA. pp. 13-15.

Collison, M. E., Fowler, K. y M. C. Boulter. 1981. Floristic changes indicate a cooling climate in the Eocene of southern England. Nature 291: 315-317.

Cronquist, A. 1981. An integrated system of classification of flowering plants. The New York Botanical Garden. Columbia University Press. New York, USA. 1261 pp.

Decaisne, J. 1846. Abelia floribunda. Flore de Serres et Jardins de 1'Europe 2: 54-56.

Ferrusquía, I. 1993. Geology of Mexico: a synopis. In: Ramamoorthy, T. P., R. Bye, A. Lot y J. Fa (eds.). Biological diversity of Mexico: origins and distribution. Oxford Univ. Press. New York, USA. pp. 3-107.

Fritsch, K. 1902. Caprifoliaceae. In: Engler, A. y K. Prantl. Die natürlichen Planzenfamilien 3: $156-167$.

Fukuoka, N. 1968. Phylogeny of the tribe Linnaeeae. Acta Phytotax. Geobot. 23: 93.

Goloboff, P. 1997. Nona (Parsimony program for windows 95/Windows NT). Published by the author. Tucumán, Argentina.

Good, R. 1974. The geography of the flowering plants. 4a. ed. Longman, London, UK. 473 pp. 
Graham, A. 1972. Outline of the origin and historical recognition of floristic affinities between Asia and Eastern North America. In: Graham, A. (ed.). Floristics and paleofloristcs of Asia and Eastern North America. Elsevier Publ. Co. Amsterdam, Holanda. pp. 1-18.

Graham, A. 1993. Historical factors and biological diversity in Mexico. In: Ramamoorthy, T. P., R. Bye, A. Lot y J. Fa (eds.). Biological diversity of Mexico: origins and distribution. Oxford Univ. Press. New York, USA. pp. 109-127.

Guzmán, E. y Z. de Cserna. 1963. Tectonic history of Mexico. Amer. Assoc. Pet. Geol. Mem. 2: 113-129.

Hara, H. 1983. A revision of Caprifoliaceae of Japan with reference to allied plants in other districts and the Adoxaceae. Ginkgoana 5: 1-336.

Hutchinson, J. 1967. The genera of flowering plants. Dicotyledons. Vol. 2. Oxford at the Clarendon Press. London, UK. pp. 81-89.

Jacobs, B., N. Pyck. y E. Smets. 2010. Phylogeny of the Linnaea clade: Are Abelia and Zabelia closely related?. Mol. Phylog. Evol. 57(2): 741-752.

Martens, M. y H. Galeotti. 1844. Enumeratio synoptica plantarum phanerogamicarum ab Henrico Galeotti in regionibus Mexicanis collectarum. Bull. Acad. Brux. 11: 242243.

Nixon, K. C. 2002. Winclada ver. 1.00.08. Published by the author. New York, USA.

Raven, P. H. y D. I. Axelrod. 1974. Angiosperm biogeography and past continental movements. Ann. Missouri Bot. Gard. 61: 539-673.

Rehder, A. 1911. Caprifoliaceae, Abelia. In: Sargent, Ch. S. Wilson expedition to China. Pl. Wilson. 1(1): 122-124.

Rzedowski, J. 1978. Vegetación de México. Ed. Limusa. México, D.F. México. 432 pp.

Sharp, A. J. 1966. Some aspects of Mexican phytogeography. Ciencia (México) 24: 229232.

Standley, P. C. 1926. Caprifoliaceae.Trees and shrubs of Mexico. Contr. U. S. Nat. Herb. 23(5): 1394-1400.

Tang, Y. C. y A. M. Lu. 2005. Paraphyletic group, PhyloCode and phylogenetic speciesthe current debate and preliminary commentary. Acta Phytotax. Sin. 43(5): 403419.

Tiffney, B. H. 1985. Perspectives on the origin of the floristic similarity between eastern Asia and eastern North America. J. Arnold Arbor. 66: 73-94.

Toledo, V. M. 1982. Pleistocene changes of vegetation in tropical Mexico. In: Prance, G. T. (ed.). The biological diversification in the tropics. Columbia Univ. Press. New York, USA. pp. 93-111.

Villarreal-Q., J. A. 1997. A new species of Abelia (Caprifoliaceae) from western Mexico. Brittonia 49: 84-86.

Villarreal-Q., J. A. y M. de la Rosa-I. 2000. Two new species of Abelia (Caprifoliaceae) from Mexico. Brittonia 52: 173-176.

Weberling, F. 1966. Zur systematischen Stellung der Caprifoliaceengattung Kolkwitzia Graebn. Blumea 14: 333-336.

Wolfe, J. A. 1975. Some aspects of plant geography of the Northern Hemisphere during the Late Cretaceous and Tertiary. Ann. Missouri Bot. Gar. 62: 264-279. 
Zabel, A. 1893. Abelia (Caprifoliaceae). Mitt. Deuts. Dendr. Ges. 2: 32.

Zhou, S. L., Funamoto, T. y J. Wen. 2004. Species relationships in Abelia sect. Abelia (Caprifoliaceae) in East Asia and verification of $A$. serrata in China evidence from AFLP analysis. Acta Bot. Yunn. 26:405-412.

Recibido en septiembre de 2010. Aceptado en agosto de 2012. 